\title{
Family Socialization Features of the Adolescents Prone to Deviant Behaviors (Gender Aspect)
}

\author{
Aigul R. Gallyamova \\ Kazan (Volga region) Federal University, Kazan, Russia \\ Email: aigul_diss@mail.ru
}

Vladimir I. Pavlov

Inna V. Vorobeva

Chuvash State Pedagogical University named after I.Y. Yakovlev, Cheboksary, Russia

Larisa I. Tararina

Elena E. Sokolova

Elizaveta V. Limarova

Ekaterina I. Sokolova

Russian State Social University, Moscow, Russia

Email: It31@mail.ru

Doi:10.5901/mjss.2015.v6n2s3p142

\begin{abstract}
The relevance of the research problem is due to the fact that deviant behavior is becoming increasingly common among adolescents, and the defects of the family socialization are one of the main reasons of this phenomenon. The article seeks to explore the impact of child-parent relationship on the propensity of adolescents toward various kinds of deviant behavior. The leading methods for the study of this problem are the psychological testing and analysis of the statistically processed obtained data. In the course of the empirical research it has been revealed that the adolescents' propensity toward deviant behavior worsens with emotional coldness, suspicion on the part of their parents, and is attenuated by the parents' psychological acceptance of their children, friendly attitude to them. The article contents can be useful for developing effective programs to reduce the adolescents' propensity toward deviant behavior.
\end{abstract}

Keywords: socialization, family, gender, femininity, masculinity, adolescents, deviant behavior.

\section{Introduction}

\subsection{The relevance of the problem}

Behavior of some children and adolescents draws attention by the violation of the norms, noncompliance with the received advice and recommendations; it differs from the behavior of those who fit into the normative demands of the family, school and society. This behavior being characterized by deviation according to the accepted moral, and in some cases, legal norms, is referred to as deviant. It includes anti-disciplinary, antisocial, and delinquent illegal and autoaggressive (suicidal and self-harming) actions. According to their origin they can be due to various deviations in the development of personality and its response (Shakurov, 2007). More often this behavior is the reaction of children and adolescents to difficult life circumstances. It is on the verge of norms and diseases and therefore should be measured not only by a teacher but also a psychologist. The possibility of variance in behavior is also associated with somatic growth, conditions of upbringing and social environment (Dmitriev, Belov, Parfenov, 2010).

Normal (adequate, adaptive) behavior of an adolescent presupposes his/her interaction with a micro-society, adequately meeting the needs and opportunities of the person's development and socialization. Hence, the deviant 
behavior can be characterized as the interaction of the child with a micro-society violating his development and socialization due to the lack of the milieu's adequate consideration of his personality characteristics, and manifesting itself in behavioral opposition to the established moral and legal social norms (Pais, 2000).

In modern society, deviant behavior has become widespread among adolescents. An important factor of the variance in psychosocial development of the child, in violation of the process of his socialization is the disharmonious, destructive attitude on the part of his/her parents. Modern scholars have identified certain styles of family relationships, leading to the formation of antisocial behavior of the minors:

1. a disharmonious style of educational and family relations, combining, on the one hand, the indulgence of the child, hyper-protection, and on the other - instigating the child's conflict situations; or characterized by double morality establishment in the family: for the family - one rule of conduct, and for the society - it is completely different;

2. an unstable, conflict style of educational influences in a single-parent family, in a situation of divorce, long-term separation of children and parents;

3. an antisocial style of relationships in a disorganized family with systematic consumption of alcohol, drugs, immoral lifestyle, criminal behavior of parents, manifestations of scarcely motivated "family cruelty" and violence (Mendelevich, Sadykova, 2004).

Violation of family socialization leads to inadequate gender identity of adolescents, therefore, the study of the impact of the child-parent relationships of the adolescents who are prone to deviant behavior, from a gender perspective, is relevant.

\subsection{The importance of the research problem}

The scientific novelty of the research lies in the fact that the relation between the child-parent relationships and the adolescents' propensity toward deviant behavior is being explored taking into the account their gender identity. The difference is being revealed in such types of characteristics as a positive interest, directivity, hostility, autonomy, inconsistency, intimacy and criticism in the relationships on the part of the mother and father, which influence the masculine and the feminine adolescents' propensity formation toward various types of deviant behavior.

The theoretical implications of the research lie in the fact that it allows expanding the understanding of the problem of propensity formation toward deviant behavior among modern adolescents, provides the opportunity to use the material for comparative studies of socio-psychological peculiarities of family and gender socialization of persons prone to various kinds of deviant behavior.

The practical implications of the research consist in the results obtained in the research and can be used in elaborating the programs of the educational process, will allow adjusting the work of teachers, psychologists, that is aimed at preventing the tendency of adolescents to deviant behavior, in order to improve the efficiency and success of their socialization. The results of the research can be used in the educational process for training specialists in the field of social psychology, sociology, psychology and pedagogy. The research materials will be particularly useful in professional development courses for psychological service employees, and educational specialists.

\subsection{Status of the problem}

The problem of deviant behavior is widely reported in foreign and domestic sociological literature, but it is important to note that its particular aspect - the adolescent deviation - has been studied to a lesser extent. Adolescent deviant behavior is a complex phenomenon, so the study of this problem has interdisciplinary and diverse nature.

The philosophical and methodological theories of foreign scientists are devoted to the study of deviance: anthropocentric theories of J. Kelly (2000), E. Kretschmer (1999), ext.; psychoanalytic theories of Z. Freud (2010), E. Erickson (2000), ext.; anomie theories of E. Durkheim (1994), R. Merton (2006); a theory of social learning of A. Bandura (2000).

Methodological foundations for the study of deviant behavior are presented also in domestic theories: deviantology of E.P. Zmanovskaya (2004), V.D. Mendelevich (2005); as well as in the writings of V.T. Lisovsky (1996), A.N. Gryaznov (2007), ext.

A significant contribution to the study of deviant behavior of adolescents was made by the authors investigating some certain aspects of this phenomenon. The works of V.G. Stepanov (2001), Shneider (2007), Zaretskiy V.K. and others (2011), I.A. Ustugova and others (2014), ext. are dedicated to the problem of adolescent deviant behavior manifestations caused by an unfavorable position of the child in the system of interfamilial relations. But the family of a 
deviant adolescent is much less common an object of a study.

\subsection{The research hypothesis}

Feminine and masculine adolescent propensity toward deviant behavior is reinforced by the emergence of negative types of relationship on the parents' part, and is attenuated by the parental acceptance of their child, friendly attitude to him/her.

\section{Materials and Methods}

\subsection{The research objectives.}

In the course of the research the following objectives were being solved: 1) a theoretical analysis of the scientific literature on the research topic; 2) selection of psycho-diagnostic tools, methods of research; 3) testing of the respondents; 4) mathematical statistics data processing methods; 5) data analysis, its theoretical interpretation, formulation of conclusions.

\subsection{Theoretical and empirical methods}

The selected research methodology, the underlying basis of which was the socio-psychological and gender-based approaches, led to the choice of the research methods and techniques. During the work the methods of empirical and theoretical levels were used. The first is the socio-psychological testing. Methods of the theoretical level were the analysis, synthesis, comparison, generalization of the results of the empirical research. When processing the results of the research the methods of statistical data analysis were used (the reliability of average (Student t-test) differences and bilateral correlation analysis (Pearson correlation coefficient).

For diagnosing the psychological gender and determining the degree of a person's androgyny, masculinity and femininity the S. Behm's (Ilyin E.P., 2003) questionnaire (survey) for gender roles assessment was used. To study the effect of the attitude on the part of the parents toward the formation of gender identity in the process of socialization the ADOR questionnaire was used, aimed at studying the attitudes, behaviors, and the parental education methods, the way their children see them during adolescence (Wasserman L.I., Gorkovskaya I.A., Romycina E.E., 2004). To determine the propensity toward deviant behavior a questionnaire "Determining the propensity toward deviant behavior" developed by A.N. Oryol was used (Clayberg Yu.A., 2004).

\subsection{The research framework}

178 adolescents aged 13-17 years were involved in the research (students of the municipal budgetary educational institution "Dzhalil comprehensive high school No.1 with in-depth study of certain subjects"). There were 96 girls and 82 boys among them. Among the girls the pronounced masculine traits were found in $33(34.4 \%)$, and the feminine - in 22 (22.9\%). The boys' pronounced masculine traits were identified in 16 (19.5 per cent), and the feminine - in $23(28,1 \%)$.

\subsection{The stages of the research}

The research was conducted in three stages:

Stage I - study of the problem of family and gender socialization of modern teenagers, analysis of the causes and identification of the factors influencing the propensity toward deviant behavior formation; definition of goals, objectives and working hypothesis of the research.

Stage II - is introduction and review of scientific literature on the research problem, collection of the statistical and analytical material to substantiate the proposed hypothesis.

Stage III - analysis and systematization of the obtained data, formulation of the conclusions and recommendations, report on the research results in the form of an article. 


\section{Results}

\subsection{The relation of gender identity and the propensity toward deviant behavior among modern teenagers}

The nature of family education is associated with the emerging defects of socialization, such as the propensity toward different types of deviant behavior. In the course of the research, using the reliability analysis of average data differences, it was ascertained that masculine adolescents have higher propensity toward addictive, self-harming and delinquent behavior, as well as to the manifestation of aggression and violence (table 1).

Table 1. Significant differences in the average values on the scales of the procedure for determining the masculine and feminine adolescent propensity toward deviant behavior (Student's t-test)

\begin{tabular}{|l|c|c|}
\hline Types of deviant behavior & $T$ & $\mathrm{p}$ \\
\hline The propensity toward breaking the rules and regulations & 0.368 & 0.715 \\
\hline The propensity toward addictive behavior & 1.622 & 0.115 \\
\hline The propensity toward self-harming and self-destructive behavior & $2.661^{*}$ & 0.012 \\
\hline The propensity toward aggression and violence & $2.654^{*}$ & 0.013 \\
\hline The emotional reactions control & 0.903 & 0.374 \\
\hline The propensity toward delinquent behavior & 1.801 & 0.082 \\
\hline
\end{tabular}

* - statistically significant differences ascertained in the average indicators at the level of significance $p \leq 0.05$

The analysis showed that masculine adolescents are more prone to self-harming and self-destructive behavior ( $\mathrm{T}=2.66$ when $p=0.012)$, as well as to the manifestation of aggression and violence $(T=2.65$ when $p=0.013)$. Therefore, they have a lower value of their own life, higher risk appetite, a stronger need for thrills. They have a stronger aggressive orientation in relationships with other people, the propensity toward solving problems by violence, the propensity toward using humiliation of a communication partner as a means for self-esteem stabilization.

\subsection{The relation between the modern adolescents' propensity toward deviant behavior and the feminine adolescents' family socialization features}

To determine the relation between the established defects of feminine and masculine adolescent socialization and the family socialization features, we carried out the correlation analysis of the obtained data with the data through the ADOR procedure. The interrelation between the feminine adolescent propensity toward deviant behavior and the attitude on the part of the mothers is presented in table 2.

Table 2. The relation between the feminine adolescent propensity toward deviant behavior and the attitude on the part of the mothers (Pearson correlation coefficient)

\begin{tabular}{|l|c|c|c|c|c|c|c|}
\hline & Positive interest & Directivity & Hostility & Autonomy & Inconsistency & Intimacy & Criticism \\
\hline The propensity toward breaking the rules and regulations & -0.367 & 0.406 & $0.480^{*}$ & -0.340 & 0.086 & $-0.446^{*}$ & 0.416 \\
\hline The propensity toward addictive behavior & -0.121 & 0.077 & 0.411 & -0.174 & 0.359 & -0.282 & 0.141 \\
\hline $\begin{array}{l}\text { The propensity toward self-harming and self-destructive } \\
\text { behavior }\end{array}$ & 0.072 & -0.297 & -0.262 & -0.244 & -0.137 & 0.177 & -0.026 \\
\hline The propensity toward aggression and violence & -0.331 & 0.080 & 0.192 & $-0.484^{*}$ & 0.017 & -0.273 & 0.317 \\
\hline The emotional reactions control & -0.194 & 0.213 & 0.204 & $-0.508^{*}$ & -0.248 & -0.209 & 0.405 \\
\hline The propensity toward delinquent behavior & 0.218 & -0.115 & -0.014 & -0.069 & 0.297 & 0.120 & -0.024 \\
\hline
\end{tabular}

**. Correlation is significant at the level 0.01 (bilateral).

*. Correlation is significant at the level 0.05 (bilateral).

In the correlation analysis it was ascertained that the feminine propensity toward breaking rules and regulations has a positive relationship of hostility from the mother ( $r=$ to 0.480 at $p \leq 0.05)$ and negative - of intimacy $(r=-0.446$ at $p \leq 0.05)$. The propensity toward aggression and violence and the control of emotional reactions have feedback of autonomy from the mother ( $r=-0.484$ at $p \leq 0.05$ and $r=-0.508$ at $p \leq 0.05$, respectively).

The relation between the feminine adolescent propensity toward deviant behavior and the attitude on the part of the fathers is presented in table 3 . 
Table 3. The relation between the feminine adolescent propensity toward deviant behavior and the attitude on the part of the fathers (Pearson correlation coefficient)

\begin{tabular}{|c|c|c|c|c|c|c|c|}
\hline & Positive interest & Directivity & Hostility & Autonomy & Inconsistency & Intimac) & Criticism \\
\hline The propensity toward breaking the rules and regulations & $0.434^{*}$ & 0.074 & -0.364 & 0.299 & 0.221 & $0.426^{*}$ & -0.225 \\
\hline The propensity toward addictive behavior & 0.201 & 0.056 & -0.013 & 0.256 & 0.251 & 0.125 & -0.119 \\
\hline The propensity toward self-harming and self-destructive behavior & 0.385 & 0.111 & -0.390 & -0.268 & -0.189 & 0.410 & 0.349 \\
\hline The propensity toward aggression and violence & 0.313 & 0.020 & -0.281 & -0.162 & -0.004 & 0.316 & 0.148 \\
\hline The motional reactions control & 0.300 & -0.125 & -0.401 & -0.021 & 0.278 & 0.365 & -0.150 \\
\hline The propensity toward delinquent behavior & 0.088 & 0.106 & 0.290 & -0.164 & 0.043 & -0.084 & 0.264 \\
\hline
\end{tabular}

**. Correlation is significant at the level 0.01 (bilateral).

*. Correlation is significant at the level 0.05 (bilateral).

It was ascertained that the feminine adolescent propensity toward breaking the rules and regulations is positively related to the interest on the part of the father $(r=0.434$ at $p \leq 0.05)$ and the intimacy $(r=0.426$ at $p \leq 0.05)$.

\subsection{The relation between the propensity toward deviant behavior among modern teenagers and the family socialization features among the masculine adolescents}

The relation between the masculine adolescent propensity toward deviant behavior and the attitude on the part of the mothers is presented in table 4 .

Table 4. The relation between the masculine adolescent propensity toward deviant behavior and the attitude on the part of the mothers (Pearson correlation coefficient)

\begin{tabular}{|l|c|c|c|c|c|c|c|}
\hline & Positive interest & Directivity & Hostility & Autonomy & Inconsistency & Intimacy & Criticism \\
\hline The propensity toward breaking the rules and regulations & -0.187 & 0.320 & $0.433^{*}$ & -0.291 & -0.029 & -0.320 & 0.337 \\
\hline The propensity toward addictive behavior & -0.099 & 0.213 & 0.268 & -0.167 & $-0.456^{*}$ & -0.189 & 0.211 \\
\hline The propensity toward self-harming and self-destructive behavior & -0.323 & -0.202 & 0.045 & -0.315 & 0.017 & -0.198 & 0.048 \\
\hline The propensity toward aggression and violence & $-0.731^{* *}$ & 0.231 & 0.339 & -0.591 & -0.086 & $-0.566^{*}$ & $0.442^{*}$ \\
\hline The emotional reactions control & -0.565 & 0.211 & $0.593^{*}$ & -0.372 & 0.073 & $-0.606^{*}$ & 0.317 \\
\hline The propensity toward delinquent behavior & 0.098 & 0.064 & -0.327 & -0.031 & $0.606^{*}$ & 0.219 & 0.053 \\
\hline
\end{tabular}

**. Correlation is significant at the level 0.01 (bilateral).

*. Correlation is significant at the level 0.05 (bilateral).

The masculine adolescent propensity toward breaking rules and regulations has a direct relation with hostility from the mother $(r=0.433$ at $p \leq 0.05)$. The propensity toward aggression and violence has feedback with a positive interest $(r=-$ 0.731 at $p \leq 0.01)$ and intimacy ( $r=-0.566$ at $p \leq 0.05)$, and also a direct relation with criticism $(r=0.442$ at $p \leq 0.05)$. The control of emotional reactions has a direct relation with hostility ( $r=0.593$ at $p \leq 0.05)$, and the inverse relation - with the intimacy $(r=-0.606$ at $p \leq 0.05)$. The propensity toward delinquent behavior has a direct relation with inconsistency on the part of the mother $(r=0.606$ at $p \leq 0.05)$.

The relation between the masculine adolescent propensity toward deviant behavior and the attitude on the part of the fathers is presented in table 5 .

Table 5. The relation between the masculine adolescent propensity toward deviant behavior and the attitude on the part of the fathers (Pearson correlation coefficient)

\begin{tabular}{|l|c|c|c|c|c|c|c|}
\hline & Positive interest & Directivity & Hostility & Autonomy & Inconsistency & Intimacy & Criticism \\
\hline The propensity toward breaking the rules and regulations & 0.035 & -0.354 & -0.109 & -0.060 & $0.507^{*}$ & 0.069 & -0.425 \\
\hline The propensity toward addictive behavior & 0.082 & -0.266 & -0.134 & -0.288 & 0.372 & 0.108 & -0.090 \\
\hline The propensity toward self-harming and self-destructive behavior & 0.290 & $0.455^{*}$ & $-0.486^{*}$ & -0.043 & $0.680^{* *}$ & 0.386 & $0.660^{* *}$ \\
\hline The propensity toward aggression and violence & 0.227 & 0.231 & -0.425 & -0.086 & -0.427 & 0.321 & 0.396 \\
\hline The emotional reactions control & 0.134 & 0.208 & -0.398 & 0.162 & -0.252 & 0.253 & 0.130 \\
\hline The propensity toward delinquent behavior & 0.279 & 0.099 & -0.179 & -0.383 & -0.182 & 0.246 & $0.497^{*}$ \\
\hline
\end{tabular}

**. Correlation is significant at the level 0.01 (bilateral).

*. Correlation is significant at the level 0.05 (bilateral). 
The masculine adolescent propensity toward breaking rules and regulations is directly related to the inconsistency on the part of the father ( $r=0.507$ at $p=\leq 0.05)$, the propensity toward self-harming and self-destructive behavior has a direct relation with directivity $(r=0.455$ at $p \leq 0.05)$, criticism ( $r=0.660$ at $p \leq 0.05)$ and inconsistency $(r=0.680$ at $p \leq 0.05)$.

\section{Discussions}

In the empirical research it was ascertained that masculine adolescents have a lower value of their own life, a higher risk appetite, and a more urgent need for thrills. They have a stronger aggressive orientation in relationships with other people, a tendency to solve problems by violence, a tendency to use humiliation of a communication partner as a means to stabilize their self-esteem.

The obtained data suggest that the feminine adolescent propensity toward denial of the existing rules and regulations, the nonconformist tendencies, negativism are worsened by emotional coldness, suspicion on their mothers' side, and are attenuated by the mothers' psychological acceptance of their children, as well as by their friendly attitude. The strengthening of these tendencies is influenced by a warm, trustful relationship and openness on the part of the father. Aggressive orientation of the person in a relationship with others, the feminine adolescent propensity toward solving problems by violence and the inability to control their emotions, the propensity toward realizing negative emotions directly in behavior, without delay, the lack of volitional control of their needs and sensual inclinations are related to low independence of the mother from the child, from his needs and interests, their low indulgence and high exactingness.

The results of the research indicate that the positive interest on the part of the masculine adolescents' fathers does not affect the propensity toward deviant behavior. The propensities toward denial of the existing rules and regulations, non-conformist tendencies, negativism are worsened by the unpredictability of the reactions on the part of the father toward the adolescent behavior, by the inability to foresee them. The readiness to realize various forms of the masculine adolescent autoaggressive behavior is increased by unpredictable, critical and authoritarian attitude of the father, and decreases with the father's desire to raise his child in accordance with the existing rules and regulations, and with the ideas about what a perfect child should be. The propensity toward illegal behavior is increased by excessive severity, injustice on the part of the father.

\section{Conclusion}

The article presents the results of the empirical research, intended to study the relation between the family socialization features and the propensity toward adolescent deviant behavior, taking into account their gender identity. The conducted research made it possible to draw conclusions about the fact that the masculine adolescent propensity toward deviant behavior is more pronounced than that of the feminine one. The feminine adolescent propensity formation toward deviant behavior is more affected by the negative manifestations of the attitude from the mother than from the father. The masculine adolescent propensity formation toward deviant behavior is approximately in the same way affected by destructive attitude both on the mothers' and the fathers' sides. In the case of psychological acceptance and closeness on the part of the parents the teenagers' propensities towards deviant behaviors decrease.

\section{References}

Bandura And. (2000). Theory of social learning. St. Petersburg: Eurasia.

Clayberg Yu.A. (2007). Workshop on a deviantologiya. - St. Petersburg: Speech.

Dmitriyev M.G., Belov V. G., Parfyonov Yu.A. (2010). Psychology and pedagogical diagnostics of delinkventny behavior at difficult teenagers. St. Petersburg: JSC PONI.

Durkheim E. (1994). Suicide: Sociological etude. Moscow: Thought.

Ericsson E. (2000). Childhood and society (2nd ed.). St. Petersburg: JSC ITD Letny sad.

Freud S. (2010). Psychology of the unconscious. St. Petersburg: St. Petersburg.

Gryaznov A.N. (2007). Tertsiarny socialization of the addiktivny personality. Kazan: Medicine.

Ilyin E.P. (2003). Differential psychophysiology of the man and woman. St. Petersburg: Piter.

Kelly Dzh. (2000) Psychology of the personality. Theory of personal constructs. Moscow: Speech.

Krechmer E. (1999) Ingenious people. St. Petersburg: Humanitarian agency "Academic Project".

Lisovsky V. T. (2006). Youth sociology. St. Petersburg: Publishing house of Sankt-Peterburzhsky university.

Mendelevich V.D. (2005). Psychology of deviant behavior. St. Petersburg: Speech.

Mendelevich V.D., Sadykova R. G. (2002) Psychology of the dependent personality, or the teenager in an environment of temptations. Kazan: RTsPNN at KMRT. 
Merton R. (2006). Social theory and social structure. Moscow: Nuclear heating plant, Keeper.

Rice F. (2000). Psychology of teenage and youthful age. St. Petersburg: St. Petersburg.

Schneider L.B. (2007). Deviant behavior of children and teenagers. Moskow: Academic project, Gaudeamus.

Shakurov R. H. (2007). Birth of the personality: new paradigm. Kazan: KGPU publishing house.

Stepanov V. G. (2001). Psychology of difficult school students (3rd ed.). Moscow: Publishing center "Akademiya".

Ustyugova I., Sukhoguzov I., Basuyeva G., Komylyatova I. (2014). Work with teenagers of deviant behavior. Volgograd: Teacher.

Wasserman L.I., Gorky I.A., Romitsyna E.E. (2004). Parents teenager's eyes: psychological diagnostics in medico-student teaching. St. Petersburg: Speech.

Zaretsky V. K., Kholmogorova A.B., Smirnova N. S., Zaretsky Yu.V., Evlashkina N. M. (2011). Three main problems of the teenager with deviant behavior. Why arise? How to help? Moskow: Forum.

Zmanovskaya E.P. (2004). Deviantologiya: Psychology of deviant behavior. Moscow: Publishing center "Akademiya". 